\title{
SOURCES OF ECONOMIC FLUCTUATIONS IN THE UNITED STATES*
}

RAY C. FAIR

There has been much recent discussion about the ultimate sources of macroeconomic variability. A number of authors attribute most of this variability to only a few sources, sometimes only one. Although there may be only a few important sources, this is far from obvious, since economies seem complicated. The purpose of this paper is to provide quantitative estimates of various sources of variability using a U. S. econometric model. Stochastic simulation is used to estimate how much the overall variances of real GNP and the GNP deflator are reduced when various shocks are suppressed in the model.

\section{INTRODUCTION}

There has been much recent discussion about the ultimate sources of macroeconomic variability. Shiller [1987] surveys this work, where he points out that a number of authors attribute most of output or unemployment variability to only a few sources, sometimes only one. The sources vary from technology shocks for Kydland and Prescott [1982], to unanticipated changes in the money stock for Barro [1977], to "unusual structural shifts," such as changes in the demand for produced goods relative to services, for Lilien [1982], to oil price shocks for Hamilton [1983], to changes in desired consumption for Hall [1986]. (See Shiller [1987] for more references.) Although it may be that there are only a few important sources of macroeconomic variability, this is far from obvious. Economies seem complicated, and it may be that there are many important sources. The purpose of this paper is to estimate the quantitative importance of various sources of variability using a macroeconometric model.

Macroeconometric models provide an obvious vehicle for estimating the sources of variability of endogenous variables. There are two types of shocks that one needs to consider: shocks to the stochastic equations and shocks to the exogenous variables. Shocks to the stochastic equations are easy to handle. They are simply draws from the postulated distribution (usually normal) of the structural error terms, the distribution upon which the estimation

*'This paper grew out of discussions with Robert Shiller, to whom I am indebted for many helpful suggestions and comments. Some of the results in this paper are cited in Shiller [1987]. This research was financed by a grant from the National Science Foundation.

c0 1988 by the President and Fellows of Harvard College and the Massachusetts Institute of Technology.

The Quarterly Journal of Economics, May 1988 
of the model is based. Shocks to the exogenous variables are less straightforward to handle. Since by definition exogenous variables are not modeled, it is not unambiguous what one means by an exogenous-variable shock. One possibility is to postulate, say, an autoregressive equation for each exogenous variable and take the error term from this equation as measuring the exogenous-variable shock. Another possibility is to postulate that exogenous-variable shocks are the errors that forecasting services make in their forecasts of the exogenous variables.

The sources of output and price ${ }^{1}$ variability are examined in this paper using my U. S. model [Fair, 1984]. The procedure that was followed, which is discussed in detail in the next section, is briefly as follows. Autoregressive equations were estimated for 23 exogenous variables in the model. These variables make up all the important exogenous variables in the model (in my view). ${ }^{2}$ These equations were then added to the model. There are 30 structural stochastic equations in the model, and so the expanded model includes 53 stochastic equations. The $53 \times 53$ covariance matrix of the error terms was then estimated. In estimating this matrix, the error terms in the structural equations were assumed to be uncorrelated with the error terms in the exogenous-variable equations, which means that the matrix was taken to be block diagonal (with a $30 \times 30$ block and a $23 \times 23$ block). This procedure is consistent with the assumption upon which the estimation of the model is based, namely that the exogenous variables are not correlated with the error terms in the structural equations. As will be seen below, this assumption has little effect on the results.

Consider now real GNP, which is one of the endogenous variables in the model. Given the estimated covariance matrix of the error terms, one can estimate the variance of GNP by means of stochastic simulation. The variance of GNP can be estimated for the one-quarter-ahead prediction, the two-quarter-ahead prediction, and so on. Let $\tilde{\sigma}^{2}$ denote the estimated variance of real GNP for some given quarter and length ahead of the prediction, where the estimated variance is based on draws of all 53 error terms in the model. Now consider fixing one of the error terms at its expected value (usually zero) and computing the variance of GNP again. In this case the stochastic simulation is based on draws of 52 error terms rather than 53 . Let $\tilde{\sigma}^{2}(k)$ denote the estimated variance of

1. Although the variability of only two endogenous variables, the level of output and the price level, is considered in this paper, the variability of any other endogenous variable in the model can be considered in the same way.

2. The 23 exogenous variables are listed in the Appendix. 
real GNP based on fixing the error term in equation $k$ at its expected value.

The difference between $\tilde{\sigma}^{2}$ and $\tilde{\sigma}^{2}(k)$ is an estimate of how much the error term in equation $k$ contributes to the variance of GNP. ${ }^{3}$ If, say, the variance of GNP falls by 5 percent when the error term for equation $k$ is not drawn, one can say that equation $k$ contributes 5 percent to the variance of GNP. It should be noted that another way to estimate this contribution would be to draw only the error term for equation $k$, compute the variance of GNP, and compare this variance with the variance when all the error terms are drawn. If the error term in equation $k$ is correlated with the other error terms in the model, these two procedures are not the same. Although there is no right or wrong way of estimating this contribution, fortunately, as will be seen, the effects of the correlation of the error terms across equations seem fairly small.

In the above discussions $k$ need not refer to just one equation. One can fix the error terms in a subset $k$ of the equations at their expected values and draw from the remaining equations. In this way one can examine the contribution that various sectors make to the variance of GNP. If the error terms across equations are correlated, then fixing, say, two error terms one at a time and summing the two differences is not the same as fixing the two error terms at the same time and computing the one difference. Again, however, the correlation across equations seems small enough to allow one to get a fairly good idea of the contribution of each error term.

It is important to realize what is and what is not being estimated in this paper. Consider an exogenous-variable shock. What is being estimated is the contribution of the error term in the exogenous-variable equation to the variance of GNP. This contribution is not the same as the multiplier effect of the exogenous variable on GNP. Two exogenous variables can have the same multiplier effects and yet make quite different contributions to the variance of GNP. If one exogenous variable fits its autoregressive equation better than does another (in the sense that its equation has a smaller estimated variance), then, other things being equal, it

3. Regarding the use of this difference as an estimate of an error term's contribution to the variance of GNP, Robert Shiller has informed me that I have been scooped by Pigou. In the second edition of Industrial Fluctuations, Pigou [1929], after grouping sources of fluctuations into three basic categories, gave his estimate of how much the removal of each source would reduce the amplitude (i.e. the standard deviation) of industrial fluctuations. He thought that the removal of "autonomous monetary causes" would reduce the amplitude by about half. Likewise, the removal of "psychological causes" would reduce the amplitude by about half. Removal of "real causes," such as harvest variations, would reduce the amplitude by about a quarter. See Shiller [1987] for more discussion of this. 
will contribute less to the variance of GNP. It is possible, of course, to use measures of exogenous-variable shocks other than error terms from autoregressive equations, and in future work this may be of interest to do, but whatever measure is used, it is not likely to be the same as the size of the multiplier.

To preview the results, they show that there are many important sources of variability for real GNP, not just one or two. They also show that the quantitative importance of many sources varies across the length of the forecast horizon. For example, the top three sources for the one-quarter-ahead prediction (inventory investment, consumption of durables, and imports) are not the same as the top three sources for the eight-quarter-ahead prediction (exports, consumption of services, and housing investment). For the GNP deflator, on the other hand, there are two main sources of variability: shocks to the price equation and shocks to the import price deflator. Shocks to the price equation are more important for the first five quarters, and shocks to the import price deflator are more important after that.

The results of this study depend on the properties of my model. If the model is a reasonably good approximation of the macroeconomy, then some weight can be placed on the conclusions. If the model is a poor approximation, then the results cannot be trusted. I have done many tests of the model, some of which are discussed in Fair [1984], and the model seems to be a reasonable approximation. In a recent test [Fair, 1987] I compared the traditional expectations hypothesis used in the model with the rational expectations (RE) hypothesis. There is very little support for the RE hypothesis, and even when the RE hypothesis is given the benefit of the doubt in the estimation of the model, the properties of this version of the model are quite similar to the properties of the regular version of the model. This is not, however, the appropriate place to defend the model. Suffice it to say that the validity of the conclusions of this paper is based on the premise that the model is a good approximation of reality.

\section{Methodology}

The General Procedure

Stochastic simulation can be used to estimate variances in nonlinear models. Write the model as

$$
f_{i}\left(y_{t}, x_{t}, \alpha_{i}\right)=u_{i t}, \quad i=1, \ldots, n, \quad t=1, \ldots, T,
$$


where $y_{t}$ is an $n$-dimensional vector of endogenous variables, $x_{t}$ is a vector of predetermined variables, $\alpha_{i}$ is a vector of unknown coefficients, and $u_{i t}$ is an error term. The first $m$ equations are assumed to be stochastic, with the remaining $u_{i t}(i=m+1, \ldots, n)$ identically zero for all $t$. It is assumed that $u_{t}=\left(u_{1 t}, \ldots, u_{m t}\right)$ is independently and identically distributed as multivariate normal $N(0, \Sigma){ }^{4}$ It is also assumed that consistent estimates of $\alpha_{i}$, denoted $\hat{\alpha}_{i}$, are available for all $i$. Given these estimates, consistent estimates of $u_{i t}$, denoted $\hat{u}_{i t}$, can be computed as $f_{i}\left(y_{t}, x_{t}, \hat{\alpha}_{i}\right)$. The covariance matrix $\Sigma$ can then be estimated as $(1 / T) \hat{U} \hat{U}^{\prime}$, where $\hat{U}$ is the $m \times T$ matrix of values of $\hat{u}_{i t}$.

Let $u_{t}^{*}$ denote a particular draw of the $m$ error terms for period $t$ from the $N(0, \hat{\Sigma})$ distribution. Given $u_{t}^{*}$ and given $\hat{\alpha}_{i}$ for all $i$, one can solve the model for period $t$. This is merely a deterministic simulation for the given values of the error terms and coefficients. Call this simulation a "trial." Another trial can be made by drawing a new set of values of $u_{t}^{*}$ and solving again. This can be done as many times as desired. From each trial one obtains a prediction of each endogenous variable. Let $y_{i t}^{j}$ denote the value on the $j$ th trial of variable $i$ for period $t$. For $J$ trials, the stochastic simulation estimate of the expected value of variable $i$ for period $t$, denoted $\tilde{\mu}_{i t}$, is

$$
\tilde{\mu}_{i t}=\left(\frac{1}{J}\right) \sum_{j=1}^{J} y_{i t}^{j} .
$$

The stochastic simulation estimate of the variance of variable $i$ for period $t$, denoted $\tilde{\sigma}_{i t}^{2}$, is

$$
\tilde{\sigma}_{i t}^{2}=\left(\frac{1}{J}\right) \sum_{j=1}^{J}\left(y_{i t}^{j}-\tilde{\mu}_{i t}\right)^{2},
$$

where $\tilde{\mu}_{i t}$ is determined in (2).

In many applications one is interested in predicted values more than one period ahead, i.e., in predicted values from dynamic simulations. The above discussion is easily modified to incorporate this case. One simply draws values for $u_{t}$ for each period of the simulation. Each trial is one dynamic simulation over the period of interest. If, for example, the period is eight quarters, one obtains eight predicted values of variable $i$ from one trial. Given the $J$

4. Although the normality assumption is used throughout this paper, other assumptions could be used. This would simply change the way the error terms are drawn. 
values of the $p$-quarter-ahead forecast of variable $i$, one can compute the mean and variance of this forecast using (2) and (3).

It should be noted that it is also possible to draw coefficients for the trials. Given an estimate of the distribution of the coefficient estimates, which one has from the estimation of the model, coefficient values can be drawn. In this case each trial consists of draws of both error terms and coefficients. This paper, however, is not concerned with uncertainty from the coefficient estimates, and only draws of the error terms are made. The coefficients are the same from trial to trial.

The next issue to consider is the treatment of the exogenous variables. If the exogenous-variable values are the same from trial to trial, then the estimated variances are conditional on fixed values of the exogenous variables. It is also possible, however, to take into account exogenous-variable uncertainty in computing the estimated variances. As noted in the Introduction, there are a number of ways in which this can be done. One straightforward way, which is done here, is to add equations explaining the exogenous variables to the model. For purposes of this paper, an eighth-order autoregressive equation (with a constant term and time trend included) was estimated for each exogenous variable of interest and these equations were added to the model. Stochastic simulation can then be done for this expanded version of the model. By drawing error terms from the equations explaining the exogenous variables, exogenous-variable uncertainty is taken into account.

Assume that there are $q$ exogenous-variable equations added to the model. This means that the covariance matrix $\Sigma$ is now $(m+q) \times(m+q)$. In estimating this matrix, one may want to take $\Sigma$ to be block diagonal, where the first block is the original $m \times m$ matrix and the second block is the $q \times q$ estimated covariance matrix of the error terms in the exogenous-variable equations. As noted in the Introduction, this procedure is consistent with the assumption upon which the estimation of the model is based.

The notation $\tilde{\sigma}_{i t}^{2}$ will be used to denote the estimated variance based on draws of all $m+q$ error terms. The notation $\tilde{\sigma}_{i t}^{2}(k)$ will be used to denote the estimated variance when the error terms in subset $k$ of the equations are fixed at their expected values, where subset $k$ can simply be one equation. Let $\tilde{\delta}_{i t}(k)$ be the difference between the two estimated variances:

$$
\tilde{\delta}_{i t}(k)=\tilde{\sigma}_{i t}^{2}-\tilde{\sigma}_{i t}^{2}(k) \text {. }
$$

In the next section, values of $\tilde{\delta}_{i t}(k)$ are computed for the one- 
through-eight-quarter-ahead predictions of real GNP and the GNP deflator for a number of different choices of $k$.

Because of the correlation of the error terms across equations, it can turn out that $\tilde{\delta}_{i t}(k)$ is negative for some choices of $k$. Also, as noted in the Introduction, it is not in general the case that $\tilde{\delta}_{i t}(k)$ for, say, $k$ equal to the first and second equations is the same as $\hat{\delta}_{i t}(k)$ for $k$ equal to the first equation plus $\tilde{\delta}_{i t}(k)$ for $k$ equal to the second equation.

\section{Computational Issues}

For a number of reasons the stochastic-simulation estimates of the variances are not exact. First, they are based on the use of estimated coefficients rather than the true values. Second, they are based on the use of an estimated covariance matrix of the error terms rather than the actual matrix. Third, they are based on a finite number of trials. Ignoring the first two reasons, it is possible to estimate the precision of the stochastic-simulation estimates for a given number of trials. In other words, it is possible to estimate the variances of $\tilde{\sigma}_{i t}^{2}$ and $\tilde{\sigma}_{i t}^{2}(k)$. What is of more concern here, however, is the variance of $\tilde{\delta}_{i t}(k)$, and this can also be estimated. The estimation of these variances is explained in the Appendix.

Stochastic-simulation error turned out to be a bigger problem than I originally thought it would be. One thousand trials was enough to make the variances of $\tilde{\sigma}_{i t}^{2}$ and $\tilde{\sigma}_{i t}^{2}(k)$ acceptably small, but without any tricks, it was not enough to make the variance of $\tilde{\delta}_{i t}(k)$ anywhere close to being acceptably small. Fortunately, there is an easy trick available. The variance of $\tilde{\delta}_{i t}(k)$ is equal to the variance of $\tilde{\sigma}_{i t}^{2}$ plus the variance of $\tilde{\sigma}_{i t}^{2}(k)$ minus twice the covariance. The trick is to make the covariance high, which can be done by using the same draws of the error terms for the computation of both $\tilde{\sigma}_{i t}^{2}$ and $\tilde{\sigma}_{i t}^{2}(k)$. Any one equation of the model, for example, requires 8,000 draws of its error term for 1,000 trials for a forecast horizon of eight quarters. If these same 8,000 numbers are used to compute both $\tilde{\sigma}_{i t}^{2}$ and $\tilde{\sigma}_{i t}^{2}(k)$, the covariance between them will be increased. When this trick is used, as shown in the Appendix, 1,000 trials lead to variances of $\tilde{\delta}_{i t}(k)$ that are acceptably small.

\section{THE MODEL}

The model is described in detail in Fair [1984], and it will only be briefly discussed here. The model has been estimated through $1986 \mathrm{II}$ for this study. The beginning quarter is $1954 \mathrm{I}$, and so there 
are 130 sample observations. There are 30 structural stochastic equations, estimated by two-stage least squares, and 98 identities. There are 23 autoregressive equations for the exogenous variables, estimated by ordinary least squares. When there was evidence of first-order serial correlation of the error term in a structural equation, the first-order serial correlation coefficient was estimated along with the other coefficients in the equation. The error terms that are relevant for the stochastic simulation work are the error terms after elimination of serial correlation. In other words, the error terms that are being dealt with are not serially correlated. The serial correlation coefficients are simply treated as structural coefficients. The eight-quarter simulation period for the simulations is 1981 III-1983 II.

Three of the main goals in developing the model were (1) to base the estimated equations on microeconomic theory, (2) to account for all flows of funds among sectors and all balance-sheet constraints, and (3) to account explicitly for possible disequilibrium effects. The stochastic equations of the model are grouped by sector: household, firm, financial, government, and foreign.

There are nine equations for the household sector: three consumption, one housing investment, four labor supply, and one demand for money. The theory behind the household equations is that households maximize a multiperiod utility function, possibly subject to a "disequilibrium" constraint regarding the amount that they can work at the current set of wage rates. The explanatory variables in the consumption, housing investment, and labor supply equations include the real value of wealth, the after-tax nominal wage, the price level, the after-tax interest rate, after-tax nonlabor income, and a "labor constraint" variable, which is designed to pick up possible disequilibrium effects. In low employment periods the specification of the consumption equations is consistent with the Keynesian story, but it differs from this story more and more (and comes closer and closer to the classical story) as the economy comes closer and closer to full employment.

The firm sector determines production (inventory investment), plant and equipment investment, employment demand, the price level, the wage rate, and its demand for money, among other things. Plant and equipment investment is a function of output and the amount of excess capital on hand, and employment demand is a function of output and the amount of excess labor on hand. The price level is a function of a demand pressure variable, the wage rate, and the import price deflator. The import price deflator has a 
fairly large effect on the domestic price level. The nominal wage rate is a function of the price level and a time trend. It is best thought of as a real wage equation.

The financial sector includes, among other equations, two term structure equations and an equation explaining stock prices. There is a demand for import equation, which is put in the foreign sector. The government sector has an interest payments equation and an equation determining unemployment benefits. Monetary policy is endogenous in the model. An interest rate reaction function is estimated, where the Fed is estimated to "lean against the wind" regarding its interest rate policy.

Interest rates have important effects in the model. They directly affect consumption, housing investment, and imports. They also affect stock prices, which affect household wealth, which affects consumption and housing investment. Plant and equipment investment is not directly affected by interest rates, but it is indirectly affected. An increase in interest rates, for example, lowers consumption and housing investment and thus sales of the firm sector, which leads to lower production and then lower plant and equipment investment.

Regarding fiscal policy, tax rates affect the after-tax wage rate and after-tax nonlabor income, which affects consumption and housing investment and thus sales of the firm sector. Government purchases of goods directly affects sales. The importance of interest rates in the model means that there is crowding out (the Fed lets interest rates rise in response to an expansionary fiscal policy action). No long-run constraints have been imposed on the model, however, and so the multiplier from a fiscal policy action is not forced to zero in the long run.

\section{THE RESUlTS}

\section{Real GNP}

The stochastic-simulation work was done in two steps. For the first step 54 stochastic simulations of 100 trials each were performed. For the first simulation none of the equations' error terms was fixed, and for each of the remaining 53 simulations one equation's error term per simulation was fixed. The variance of $\tilde{\delta}_{i t}(k)$ depends on the size of $\tilde{\delta}_{i t}(k)$, and when the size is quite small, sufficient accuracy can be obtained with 100 trials. The first step thus allowed one to determine those equations whose error terms 
TABLE I

VARIANCE DECOMPOSITION FOR REAL GNP

\begin{tabular}{|c|c|c|c|c|c|c|c|c|}
\hline & \multicolumn{8}{|c|}{ Quarters ahead } \\
\hline & 1 & 2 & 3 & 4 & 5 & 6 & 7 & 8 \\
\hline \multicolumn{9}{|l|}{ Demand shocks } \\
\hline Consumption of services & 9.0 & 9.3 & 9.1 & 9.2 & 9.5 & 9.8 & 8.8 & 8.7 \\
\hline Consumption of nondurables & 5.2 & 7.0 & 6.3 & 4.6 & 5.7 & 4.2 & 3.2 & 2.3 \\
\hline Consumption of durables & 18.8 & 15.9 & 12.9 & 10.1 & 8.5 & 6.3 & 6.8 & 5.0 \\
\hline Housing investment & 11.1 & 12.2 & 9.4 & 15.4 & 14.6 & 12.9 & 10.8 & 8.2 \\
\hline Inventory investment & 28.7 & 17.3 & 9.8 & 6.9 & 6.7 & 2.3 & 5.5 & 4.4 \\
\hline P \& E investment & 5.8 & 4.3 & 4.0 & 2.6 & 2.5 & 2.8 & 2.9 & 2.2 \\
\hline \multicolumn{9}{|l|}{$\begin{array}{l}\text { Demand for (1) workers } \\
\text { (2) hours per worker }\end{array}$} \\
\hline (3) overtime hours & -1.1 & -1.4 & -0.9 & -0.8 & -0.8 & -0.8 & -0.8 & -0.4 \\
\hline Imports & -14.7 & -9.6 & -4.3 & -1.2 & -1.2 & 3.0 & 5.1 & 6.7 \\
\hline Exports & 13.9 & 15.0 & 16.0 & 19.7 & 21.6 & 21.0 & 20.9 & 18.6 \\
\hline Total & 77.1 & 71.5 & 65.8 & 71.3 & 72.7 & 67.8 & 69.1 & 62.2 \\
\hline Total $^{b}$ & 88.1 & 81.0 & 75.4 & 70.3 & 67.1 & 61.8 & 59.1 & 53.5 \\
\hline \multicolumn{9}{|c|}{ Money demand, long-term interest rate, and stock price shocks } \\
\hline \multicolumn{9}{|c|}{$\begin{array}{l}\text { Demand for money: } \\
\text { (1) household } \\
\text { (2) firms }\end{array}$} \\
\hline (3) currency & -0.0 & -0.2 & -1.1 & -1.9 & -1.4 & -1.9 & -2.1 & -1.5 \\
\hline Bond rate and mortgage rate & 1.4 & 2.1 & 2.2 & 2.3 & 2.0 & 2.7 & 3.5 & 3.9 \\
\hline Stock prices & 0.0 & 1.2 & 2.6 & 4.0 & 5.0 & 5.9 & 5.7 & 6.1 \\
\hline Total ${ }^{\mathrm{e}}$ & 1.4 & 3.1 & 3.7 & 4.4 & 5.6 & 6.7 & 7.1 & 8.5 \\
\hline Total & 1.4 & 3.1 & 4.0 & 4.8 & 6.1 & 7.4 & 7.8 & 9.1 \\
\hline
\end{tabular}

contribute very little to the overall variance. There were 11 such equations. ${ }^{5}$ This left 43 equations to consider further.

For the second step 30 simulations of 1,000 trials each were run. The first simulation was again where none of the equations' error terms was fixed. Each of the other 29 simulations consisted of fixing one or more of the remaining 43 equations' error terms. ${ }^{6}$ The results for real GNP are presented in Table $I$. Each number in Table $I$ is the difference between the two variances as a percent of

5. The variables explained by the 11 equations are (1) labor force participation of men 25-54, (2) labor force participation of women 25-54, (3) labor force participation of all others 16 and over, (4) number of people holding two jobs, (5) dividend payments of the firm sector, (6) interest payments of the firm sector, (7) inventory valuation adjustment, (8) capital consumption of the firm sector, (9) member bank borrowing from the Federal Reserve, (10) unemployment insurance benefits, (11) interest payments of the Federal government.

6. Each (eight-quarter) simulation of 1,000 trials takes about five hours of $\mathrm{CPU}$ time on a VAX 730. The 30 simulations thus took about a week of CPU time. Counting initial experimentation time, various false starts, and some errors, the computer work for this paper took about a month of CPU time. 
TABLE I

(Continued)

\begin{tabular}{|c|c|c|c|c|c|c|c|c|}
\hline & \multicolumn{8}{|c|}{ Quarters ahead } \\
\hline & 1 & 2 & 3 & 4 & 5 & 6 & 7 & 8 \\
\hline \multicolumn{9}{|l|}{ Supply shocks } \\
\hline$\overline{\text { Domestic price deflator }}$ & 1.3 & 2.4 & 3.7 & 4.9 & 5.5 & 6.4 & 6.5 & 6.8 \\
\hline Wage rate & 0.7 & 0.9 & 1.2 & 0.9 & 1.6 & 1.7 & 1.8 & 3.8 \\
\hline Import price deflator & -0.4 & -0.7 & -1.1 & -1.8 & -2.7 & -3.1 & -3.4 & -3.4 \\
\hline \multicolumn{9}{|l|}{$\begin{array}{l}\text { Population (1) men 25-54 } \\
\text { (2) women 25-54 }\end{array}$} \\
\hline (3) all others $16+$ & 0.4 & 0.3 & 0.9 & 0.8 & 0.6 & 0.4 & 0.2 & 0.4 \\
\hline Total $^{a}$ & 2.0 & 2.9 & 4.7 & 4.8 & 5.0 & 5.4 & 5.1 & 7.6 \\
\hline Total $^{\mathrm{b}}$ & 2.1 & 3.0 & 4.6 & 4.6 & 4.9 & 5.3 & 5.1 & 7.2 \\
\hline \multicolumn{9}{|c|}{ Fiscal shocks ( $F=$ federal, $S=$ state and local) } \\
\hline$F$ purchases of goods & 7.9 & 6.1 & 6.2 & 5.5 & 6.0 & 6.3 & 7.0 & 6.9 \\
\hline Five $F$ tax rates & -0.1 & -0.3 & -0.0 & 0.9 & 2.2 & 3.5 & 4.0 & 3.6 \\
\hline $\begin{array}{l}\text { Three } F \text { demand for workers } \\
\text { and hours variables }\end{array}$ & 1.1 & 1.4 & 1.8 & 1.7 & 1.5 & 1.4 & 1.5 & 1.7 \\
\hline $\begin{array}{l}F \text { transfer payments to house- } \\
\text { holds }\end{array}$ & -1.1 & -2.0 & -1.2 & -1.5 & -2.4 & -2.3 & -2.2 & -2.2 \\
\hline$S$ purchases of goods & 2.3 & 2.6 & 2.9 & 2.9 & 3.0 & 3.2 & 3.4 & 4.0 \\
\hline Five $S$ tax rates & 0.1 & 0.3 & 0.5 & 0.6 & 1.2 & 1.7 & 2.6 & 3.0 \\
\hline $\begin{array}{l}\text { One } S \text { demand for workers } \\
\text { variable }\end{array}$ & 0.4 & 0.7 & 0.6 & 0.4 & 0.4 & 0.7 & 0.8 & 1.0 \\
\hline$S$ transfer payments to house- & 00 & & & 00 & & & & \\
\hline Total $^{\mathrm{a}}$ & $\begin{array}{r}0.0 \\
10.6\end{array}$ & $\begin{array}{l}0.1 \\
8.9\end{array}$ & $\begin{array}{r}0.4 \\
11.2\end{array}$ & $\begin{array}{r}0.9 \\
11.4\end{array}$ & $\begin{array}{r}0.8 \\
12.7\end{array}$ & $\begin{array}{r}0.7 \\
15.2\end{array}$ & $\begin{array}{r}0.7 \\
17.8\end{array}$ & $\begin{array}{r}0.6 \\
18.6\end{array}$ \\
\hline Total $^{\mathrm{b}}$ & 10.2 & 8.5 & 10.5 & 11.4 & 13.8 & 16.7 & 19.5 & 20.5 \\
\hline Interest rate reaction function & locks & & & & & & & \\
\hline Interest rate reaction function & -0.0 & 0.8 & 2.0 & 2.9 & 2.9 & 2.8 & 2.8 & 3.1 \\
\hline
\end{tabular}

Notes. $\mathrm{a}$ = sum of individual values. $\mathrm{b}$ - computed from stochastic simulation with all the relevant error terms set to zero at the same time.

the overall variance (in percentage points). In terms of the above notation, each number is $100\left[\tilde{\delta}_{i t}(k) / \tilde{\sigma}_{i t}^{2}\right]$.

The results in Table I are divided into five categories: (1) demand shocks; (2) money demand, long-term interest rate, and stock price shocks; (3) supply shocks; (4) fiscal shocks; and (5) shocks from the interest rate reaction function, which can be interpreted as monetary policy shocks. This grouping is somewhat arbitrary, but it is useful for organizing the discussion.

Consider demand shocks first. Nine demand shocks were analyzed: three types of consumption, three types of investment, labor demand, imports, and exports. For each of the nine simula- 
tions, one equation's error term was fixed except for the simulation regarding labor demand, where three equations' error terms were fixed. In addition, a tenth simulation was run in which the error terms in all 11 equations were fixed. The first total for the demand shocks in Table $I$ is the sum of the nine individual values, and the second total is the value computed from the tenth simulation. The difference between the two totals is an indication of how much the correlation of the error terms across equations matters. If each of the 11 error terms were uncorrelated with all the other error terms in the model, the two totals would be the same. Similar comparisons for the other groupings are presented in Table I. Only for the demand shocks do the correlations matter much at all. The largest difference for the demand shocks is 11 percentage points: 77.1 percent versus 88.1 percent for the one-quarter-ahead prediction. The effects of the correlation of the error terms across equations thus seem moderate. ${ }^{7}$ In what follows, the discussion of the totals will focus on the first total, i.e., the sum of the individual values.

The demand shocks account for about 70 percent of the variance of GNP. The first-quarter value is 77.1 percent, and the range for the other seven values is 62.2 to 72.7. Although the total does not vary much across the forecast horizon, a number of the individual percents do. Consumption of durables falls from 18.8 to 5.0 ; inventory investment falls from 28.7 to 4.4 ; and imports rise from -14.7 to 6.7 . The contribution of three categories-consumption of nondurables, plant and equipment investment, and labor demand-is small for all quarters. It is clearly the case that the household sector's equations-three consumption and one housing investment-contribute much more than do the firm sector's equations - two investment and three labor demand - to the variance of GNP. Note that the result that plant and equipment investment shocks have a small effect does not mean that plant and equipment investment is somehow unimportant in the model. It simply means that the effects of the shocks to the plant and equipment investment equation are relatively small.

Fiscal shocks are the second largest contributor to the variance of GNP in Table I. The percents range from 8.9 to 18.6 within the

7. Another example of this, as noted in the Introduction, is that the block diagonal assumption about the $53 \times 53$ covariance matrix does not seem to matter much. This was tested by comparing two stochastic simulations, each with all 53 error terms drawn, but one using the block diagonal covariance matrix and one using the full matrix. For all eight quarters the variances of real GNP using the full matrix were larger, but the differences were small. The percentage differences between the two estimated variances for the eight quarters were, respectively, $1.6,4.2,4.6,4.5,2.7$, $2.9,4.6$, and 4.5 . 
forecast horizon. The percents for tax rates and transfer payments generally increase across the horizon. The two main sources of fiscal shocks are federal purchases of goods and state and local purchases of goods.

Supply shocks account for a rising proportion of the variance across the horizon, but the percent at the end of 7.6 is still fairly small. Similarly, money demand, long-term interest rate, and stock price shocks account for a rising proportion of the variance across the horizon. The percent at the end is 8.5. The effects of the shocks to the interest rate reaction function are small, the largest percent reaching only 3.1. Although the shocks to the interest rate reaction function do not contribute very much, this does not mean that the Fed itself is ineffective and that monetary policy is not important in the model. (Monetary policy is in fact quite important in the model; see, for example, the results in Fair [1984, Ch. 9].) Again, it simply means that the effects of the shocks to the reaction function are relatively small.

It was noted above that when the interest rate reaction function is included in the model, as it is for all the simulations in this study, monetary policy is endogenous. This means that the demand for money equations directly affects the short-term interest rate only because the lagged growth of the money stock is an explanatory variable in the interest rate reaction function. It is not the case, for example, that the money supply is fixed and that shocks to the money demand equations directly affect the interest rate. It is thus not surprising that the shocks to the money demand equations contribute very little to the variance of GNP. They would contribute much more if the money supply were taken to be exogenous (and thus the interest rate reaction function dropped).

To summarize, the results show that the contributions from the various sources vary across the length of the forecast horizon. They also show for any given length that no one or two sources dominate. The totals for the demand shocks are the largest, but there are many different types of demand shocks. For the onequarter-ahead prediction, the top five contributions are 28.7 percent for inventory investment, 18.8 percent for the consumption of durables, -14.7 percent for imports, 13.9 percent for exports, and 11.1 percent for housing investment. For the eight-quarter-ahead prediction, the top five are 18.6 percent for exports, 8.7 percent for the consumption of services, 8.2 percent for housing investment, 6.9 percent for federal government purchases of goods, and 6.8 percent for the domestic price deflator. 


\section{GNP Deflator}

The results for the GNP deflator are presented in Table II. They are based on the same stochastic simulations as those used for the GNP results. The results for the GNP deflator are easier to discuss because fewer shocks matter. There are two main sources of variability, shocks to the price equation and shocks to the import price deflator. Most of the variability for the first few quarters is due to shocks to the price equation, but after five quarters, shocks to the import price deflator become more important. Eight quarters out, demand shocks contribute 4.6 percent and fiscal shocks contribute 8.7 percent. There are two reason for the importance of the shocks to the import price deflator. The first is that the import price deflator has a large effect on the domestic price level in the domestic price equation. The second is that the autoregressive import price equation has a fairly large variance. There are thus large shocks to the import price deflator in the stochastic simulations, which have a large impact on the variance of the GNP deflator through the price equation.

TABLE II

VARIANCE DECOMPOSITION FOR THE GNP DEFLATOR

\begin{tabular}{|c|c|c|c|c|c|c|c|c|}
\hline & \multicolumn{8}{|c|}{ Quarters ahead } \\
\hline & 1 & 2 & 3 & 4 & 5 & 6 & 7 & 8 \\
\hline \multicolumn{9}{|l|}{ Demand shocks } \\
\hline Total $^{\mathrm{b}}$ & 3.1 & 2.3 & 2.9 & 2.3 & 1.7 & 3.3 & 4.1 & 4.6 \\
\hline \multicolumn{9}{|c|}{ Money demand, long-term interest rate, and stock price shocks } \\
\hline $\begin{array}{l}\text { Total } \\
\text { Supply shocks }\end{array}$ & -0.0 & -0.0 & -0.1 & -0.0 & -0.2 & -0.3 & -0.4 & -0.4 \\
\hline Domestic price deflator & 83.4 & 75.8 & 65.8 & 56.0 & 44.2 & 34.8 & 26.8 & 21.5 \\
\hline Wage rate & 2.8 & 4.8 & 6.5 & 6.6 & 5.6 & 4.0 & 3.0 & 2.4 \\
\hline Import price deflator & 0.8 & 4.8 & 13.1 & 21.2 & 31.3 & 41.0 & 50.3 & 58.3 \\
\hline $\begin{array}{l}\text { Population (1) men } 25-54 \text {, } \\
\text { (2) women } 25-54 \text {, }\end{array}$ & & & & & & & & \\
\hline (3) all others $16+$ & 0.0 & -0.2 & -0.4 & -0.5 & -0.6 & -0.6 & -0.8 & -0.6 \\
\hline Total $^{\mathrm{a}}$ & 87.0 & 85.2 & 85.0 & 83.3 & 80.5 & 79.2 & 79.3 & 81.6 \\
\hline Total $^{\mathrm{b}}$ & 89.7 & 87.5 & 85.1 & 84.5 & 83.5 & 83.3 & 84.0 & 85.3 \\
\hline \multicolumn{9}{|l|}{ Fiscal shocks } \\
\hline Total $^{\mathrm{b}}$ & 8.1 & 10.4 & 11.1 & 11.4 & 11.6 & 11.1 & 9.2 & 8.7 \\
\hline \multicolumn{9}{|c|}{ Interest rate reaction function shocks } \\
\hline Interest rate reaction function & -0.0 & -0.1 & -0.3 & -0.3 & -0.2 & 0.0 & 0.1 & 0.2 \\
\hline
\end{tabular}

Notes. $\mathbf{a}=$ sum of individual values. $\mathrm{b}=$ computed from stochastic simulation with all the releyant error terms set to zero at the same time. 


\section{Comparison with Other Results}

It is of interest to compare the present results with those of Blanchard and Watson [1986] (BW). Using a four-equation model, $B W$ provide estimates of the percent of the variance of GNP due to four shocks: demand, supply, money supply, and fiscal. ${ }^{8}$ (The BW model does not require stochastic simulation to compute the variances.) Their demand shocks are probably closest to the first two categories of shocks in Table I (demand plus money demand, long-term interest rate, and stock price). For the one-quarter-ahead forecast, BW estimate that 74.0 percent of the variance of GNP is due to demand shocks. The relevant number in Table $\mathrm{I}$ is $77.1+$ $1.4=78.5$ percent. For the four-quarter-ahead forecast, the BW estimate is 54.0 percent, which compares with $71.3+4.4=75.7$ in Table I. The supply shocks are 3.0 for BW versus 2.0 in Table I for the one-quarter-ahead forecast and 15.0 versus 4.8 for the fourquarter-ahead forecast. The fiscal shock comparisons are 19.0 versus 10.6 for one quarter ahead and 16.0 versus 11.4 for four quarters ahead. The BW money supply shocks are closest to the shocks to the interest rate reaction function here. The comparisons are 4.0 versus -0.0 for one quarter ahead and 16.0 versus 2.9 for four quarters ahead. The main differences in these results is that four quarters out the present results show more contribution from the demand and fiscal shocks and less from the supply and monetary reaction shocks than do the BW results. In general, however, the results are fairly similar.

Regarding the variance of the GNP deflator, BW attribute about three fourths of the variance to supply shocks and about one fourth to demand shocks for one quarter ahead. (The effects of the other shocks are minor.) The values four quarters ahead are two thirds and one third. In Table II about 85 percent of the variance is attributed to supply shocks (for all quarters ahead), with demand shocks accounting for about 3 percent and fiscal shocks for about 10 percent. The present results thus attribute more of the variance to supply shocks. Remember, however, that the total for the supply shocks masks important individual differences-in this case the shocks to the domestic price equation versus shocks to the import price deflator. The import price deflator is not a variable in the BW model.

Finally, Bernanke [1986] has employed the BW methodology

8. The results cited here are taken from Blanchard and Watson [1986, Table 2.3, p. 133]. 
to estimate a number of small models and then to provide estimates of the decomposition of the variance of output. For the "MoneyCredit" model, ${ }^{9} 53.3$ percent of the variance of output is attributed to demand shocks eight quarters out, which compares with 62.2 percent in Table I. Fiscal shocks account for 12.1 percent, compared with 11.4 in Table I, and supply shocks account for 12.4 percent, compared with 7.6 in Table $\mathrm{I}$. The main difference here is that Bernanke attributes less to the demand shocks than is the case in Table I.

\section{CONCLUSION}

The methodology of this study allows one to get a good idea of the quantitative contribution of various shocks to the variance of endogenous variables like real GNP and the GNP deflator. For the variance of the GNP deflator, there are two main sources of variability: shocks to the price equation and shocks to the import price deflator. For the variance of real GNP there are many important shocks; it is clearly not the case that one or two shocks dominate. Also, the importance of many shocks varies across the forecast horizon. There are thus no simple stories to be told about the sources of output variability, at least not within the context of a macroeconometric model like the one used in this paper.

\section{APPENDIX}

The calculation of the simulation-error variances is discussed in this Appendix, and some examples are presented. In the text $y_{i t}^{j}$ denotes the predicted value of variable $i$ for period $t$ on the $j$ th trial. For purposes of this Appendix, the "it" subscript will be dropped. The following discussion always pertains to variable $i$ for period $t$. The stochastic-simulation estimate of the expected value of variable $i$ for period $t$ is given by equation (2) in the text, which is repeated here in the current notation:

$$
\tilde{\mu}=\left(\frac{1}{J}\right) \sum_{j=1}^{J} y^{j}
$$

Let

$$
\sigma^{2 j}=\left(y^{j}-\tilde{\mu}\right)^{2}
$$

9. The results cited here are taken from Bernanke [1986, Table 5, p. 74]. 
The stochastic-simulation estimate of the variance of variable $i$ for period $t$, which is given by equation (3) in the text, is then

$$
\tilde{\sigma}^{2}=\left(\frac{1}{J}\right) \sum_{j=1}^{J} \sigma^{2 j}
$$

An estimate of the variance of $\tilde{\sigma}^{2}$, denoted $\operatorname{var}\left(\tilde{\sigma}^{2}\right)$, is

$$
\operatorname{var}\left(\tilde{\sigma}^{2}\right)=\left(\frac{1}{J}\right)^{2} \sum_{j=1}^{J}\left(\sigma^{2 j}-\tilde{\sigma}^{2}\right)^{2} .
$$

(Note also that an estimate of the variance of $\tilde{\mu}$ is $\tilde{\sigma}^{2} / J$, although this estimate is not needed for the present analysis.)

As in the text, the notation $(k)$ will be used to denote a stochastic simulation where the error terms in subset $k$ of the equations are fixed at their expected values. Let

$$
d^{j}(k)=\sigma^{2 j}-\sigma^{2 j}(k) .
$$

The estimated mean of $d^{j}(k)$, denoted $\tilde{\delta}(k)$, is

$$
\tilde{\delta}(k)=\left(\frac{1}{J}\right) \sum_{j=1}^{J} d^{j}(k) .
$$

Equation (A6) is the same as equation (4) in the text. $\tilde{\delta}(k)$ is the difference between the two estimated variances. The estimated variance of $\tilde{\delta}(k)$, denoted $\operatorname{var}[\tilde{\delta}(k)]$, is then

$$
\operatorname{var}[\tilde{\delta}(k)]=\left(\frac{1}{J}\right)^{2} \sum_{j=1}^{J}\left[d^{j}(k)-\tilde{\delta}(k)\right]^{2} .
$$

Given values of $y^{j}$ and $y^{j}(k), j=1, \ldots, J$, all the above values can be computed.

The results in Table III give one an idea of the precision of the estimates based on 1,000 trials. These are the results used in the paper for real GNP. The units are in billions of 1982 dollars. The first row in Table III presents the estimates of the variance of real GNP, and the second row presents the estimated standard errors of the variance estimates. The variance estimates are fairly precise, with estimated standard errors less than 5 percent of the variance estimates. The next two rows pertain to the stochastic simulation in which the error term in the export equation is fixed. The values of the difference are presented in the first of the two rows, and the estimated standard errors of the difference values are presented in the second of the two rows. The same two rows are presented for the stimulation in which the error term in the stock price equation is 
TABLE III

Precision of the Stochastic Simulation Estimates for Real GNP

\begin{tabular}{|c|c|c|c|c|c|c|c|c|}
\hline & \multicolumn{8}{|c|}{ Quarters ahead } \\
\hline & 1 & 2 & 3 & 4 & 5 & 6 & 7 & 8 \\
\hline $\begin{array}{l}\tilde{\sigma}^{2} \\
\left\{\operatorname{var}\left(\tilde{\sigma}^{2}\right)\right\}^{1 / 2}\end{array}$ & $\begin{array}{l}400.2 \\
(17.5)\end{array}$ & $\begin{array}{l}807.1 \\
(32.8)\end{array}$ & $\begin{array}{r}1250.7 \\
(52.6)\end{array}$ & $\begin{array}{r}1689.3 \\
(69.2)\end{array}$ & $\begin{array}{r}2212.5 \\
(93.2)\end{array}$ & $\begin{array}{l}2616.1 \\
(109.8)\end{array}$ & $\begin{array}{l}3207.4 \\
(135.4)\end{array}$ & $\begin{array}{l}3512.3 \\
(153.5)\end{array}$ \\
\hline \multicolumn{9}{|c|}{ Error term in the export equation fixed } \\
\hline $\begin{array}{l}\tilde{\delta}(k) \\
\{\operatorname{var}[\tilde{\delta}(k)]\}^{1 / 2}\end{array}$ & $\begin{array}{l}53.3 \\
(8.8)\end{array}$ & $\begin{array}{l}121.1 \\
(20.5)\end{array}$ & $\begin{array}{l}199.9 \\
(32.4)\end{array}$ & $\begin{array}{l}332.0 \\
(44.9)\end{array}$ & $\begin{array}{l}478.7 \\
(62.5)\end{array}$ & $\begin{array}{l}549.6 \\
(78.3)\end{array}$ & $\begin{array}{l}670.5 \\
(91.9)\end{array}$ & $\begin{array}{c}654.9 \\
(103.7)\end{array}$ \\
\hline \multicolumn{9}{|c|}{ Error term in the stock price equation fixed } \\
\hline $\begin{array}{l}\tilde{\delta}(k) \\
\{\operatorname{var}[\tilde{\delta}(k)]\}^{1 / 2}\end{array}$ & $\begin{array}{c}0.005 \\
(0.006)\end{array}$ & $\begin{array}{c}9.3 \\
(2.1)\end{array}$ & $\begin{array}{l}32.9 \\
(5.9)\end{array}$ & $\begin{array}{c}66.8 \\
(10.6)\end{array}$ & $\begin{array}{l}110.4 \\
(16.9)\end{array}$ & $\begin{array}{l}153.7 \\
(23.7)\end{array}$ & $\begin{array}{l}184.4 \\
(31.4)\end{array}$ & $\begin{array}{l}214.1 \\
(37.7)\end{array}$ \\
\hline
\end{tabular}

Notes, Units are billions of 1982 dollars. Estimates are based on 1,000 trials. 
fixed. For both of these variables the standard errors are around 15 percent of the difference values.

For all the stochastic simulations the standard errors of the difference values seemed small enough to allow meaningful comparisons to be made, although they are still fairly far from zero. Remember that these estimates are based on the trick of using the same draws for both simulations. Without this trick, the standard errors are much too large for anything meaningful to be done with the difference values.

Finally, the 23 exogenous variables for which autoregressive equations were estimated are the following:

1. Federal purchases of goods

2. Federal personal income tax parameter

3. Federal corporate tax rate

4. Federal indirect business tax rate

5. Federal employer social security tax rate

6. Federal employee social security tax rate

7. Federal transfer payments to households

8. Federal civilian employment

9. Federal military employment

10. Federal hours paid per worker

11. State and local purchases of goods

12. State and local personal income tax parameter

13. State and local corporate tax rate

14. State and local indirect business tax rate

15. State and local employer social security tax rate

16. State and local employee social security tax rate

17. State and local transfer payments to households

18. State and local employment

19. Exports

20. Price of imports

21. Population of men $25-54$

22. Population of women $25-54$

23. Population of all others 16 and over.

YALE UNIVERSITY

\section{REFERENCES}

Barro, Robert J., "Unanticipated Money Growth and Unemployment in the United States," American Economic Review, LXVII (March 1977), 101-15.

Bernanke, Ben S., "Alternative Explanations of the Money-Income Correlation," in Karl Brunner and Allan H. Meltzer, eds., Real Business Cycles, Real Exchange Rates and Actual Policies (Amsterdam: North-Holland, 1986). 
Blanchard, Olivier J., and Mark W. Watson, "Are Business Cycles All Alike?" in Robert J. Gordon, ed., The American Business Cycle: Continuity and Change (Chicago: NBER and University of Chicago Press, 1986).

Fair, Ray C., Specification, Estimation, and Analysis of Macroeconometric Models (Cambridge: Harvard University Press, 1984).

- "The Use of Expected Future Variables in Macroeconometric Models," mimeo, 1987.

Hall, Robert E. "The Role of Consumption in Economic Fluctuations," in Robert J. Gordon, ed., The American Business Cycle: Continuity and Change (Chicago: NBER and University of Chicago Press, 1986).

Hamilton, James D., "Oil and the Macroeconomy since World War II," Journal of Political Economy, XCI (April 1983), 228-48.

Kydland, Finn E., and Edward C. Prescott, "Time to Build and Aggregate Fluctua" tions," Econometrica, L (1982), 1345-70.

Lilien, David M. "Sectoral Shifts and Cyclical Unemployment," Journal of Political Economy, XC (August 1982), 777-93.

Pigou, Arthur C., Industrial Fluctuations, 2nd ed. (London: Macmillan, 1929).

Shiller, Robert J., "Ultimate Sources of Aggregate Variability," American Economic Review, LXXVII (May 1987), 87-92. 